\title{
Enhancement Surface Coating Stainless Steel And Copper Using Ultrasonic Batch
}

\author{
Sendie Yuliarto Margen*, Sulistyo S, Sri Nugroho, Yoga Setiawan Adi Nugroho \\ Mechanical Engineering Department, Engineering Faculty, Diponegoro University, Semarang, \\ Central Java, 50275, Indonesia.
}

\begin{abstract}
Electrodeposition is considered an easy and cost effective technique for the manufacture of alloy layers. Various properties for coatings can be achieved by selecting various electrodeposition parameters. These materials have the advantage of corrosion resistance but relatively expensive. They will need alternative materials that can easily obtained and replace these materials. This paper discusses the process of coating stainless steel AISI 304 and copper with Ni. Electric current and coating time is used in the electroplating coating process of $\mathrm{Ni}$ to $\mathrm{Ni}$ thickness supported by ultrasonic batch. AISI 304 stainless steel and copper coated using nickel $(\mathrm{Ni})$ with variable time and fixed electric current parameters. The electric current used 1.5 ampere, the time of plating process of 60 seconds, 120 seconds, and 180 seconds. The composition of nickel electrolyte solutions using nickel sulfate $300 \mathrm{gr} / \mathrm{L}$, nickel chloride $30 \mathrm{gr} / \mathrm{L}$, and sour borax $30 \mathrm{gr} / \mathrm{L}$ with brighteners added one (I) $15 \mathrm{~mL}$ and brighteners two (II) $1 \mathrm{~mL}$. Measurement of thickness is done by using optical microscope assisted by imageraster software. The best process used 1.5 amperes of electric current and time of 180 seconds. The value of copper thickness is $26.50(\mu \mathrm{m})$ using ultrasonic batch.
\end{abstract}

\section{Introduction}

Coating is a technology that is well known in the field of industry. The advantage of coating technique is to improve the quality of the material. Its quality that can be improved include mechanical properties, physical properties, chemical properties and decorations. Increased mechanical properties are resistance to wear and increased hardness, chemical properties of coated material can be corrosion resistant, while the physical properties is to smooth the surface of the sighting side. Coating technology can be carried out by various process methods such as Physical Vapor Deposition (PVD), Chemical Vapor Deposition (CVD), spraying, deep coating and electroplating. [1,2].

The method of coating that has been developed has its own unique advantages. PVD was developed to produce a thin layer with a range of nanometer thickness up to a micrometer in a vacuum. The formed layer is obtained from the conversion of materials in the form of atoms or molecules from the evaporation process of a precipitated material

\footnotetext{
${ }^{*}$ Corresponding author : sendiemargen@gmail.com
} 
under vacuum conditions [3]. Electroplating is the process of solving the coating in a solution assisted by the flow of electricity. The quality of the electroplating coating is influenced by the type of solution and the current flowed through the electrode [4].

Principally of the electroplating process, the electricity flows between the anode and the cathode, in aqueous electrolyte solution and the chemical reaction on the metal surface occurs. When given the potential difference or voltage, ions move toward the electrode. The cation moves toward the cathode and anion toward the anode. This process occurs by catalyzing a chemical reaction to reduce the metal salt (anode). The thickness range that can be obtained by electroless process is $1-120 \mu \mathrm{m}$. The coating process is always through several stages : surface cleaning to be coated, surface activation, coating process, and after coating treatment $[5,6]$.

The electroplating process is based on Faraday's law that (1) the mass is released to an electrolyte solution which is proportional to the current through a large electrolyte solution and (2) the released mass is proportional to the electrochemical equivalent (atomic valence ratio). The workpiece was coated by electroplating included iron, steel, bronze, copper, plastic, and stainless steel. The transfer of metal ions was helped by an electric current through the electrolyte solution. The metal ions precipitates on solid objects. The metal ion is obtained from the electrolyte solution as well as derived from the dissolving metal anode in the electrolyte. Deposition occurs on the workpiece acting as a cathode [7,8]. AISI 304 stainless steel and copper have been selected as substrate. Nickel (Ni) is used as a coating as a material because it can improve corrosion resistance at high temperature of AISI 304 stainless steel and copper as an alternative material. Electroplating process can be improved coating quality by using ultrasonic batch [9].

Ultrasonic batch is process that use ultrasound waves (typically from 20-400 kHz). The ultrasonic process can improve the coating due to fluid agitation. Agitation produces high strengths on contaminants attached to substrates such as metals, copper, plastics, glass, rubber, and ceramics. This action also penetrates the holes, cracks, and niches of the blind. The ultrasound transducer generator is installed indoors, or lowered into the liquid. Ultrasonic waves are produced in liquids by changing the particle size inside the tank by using an oscillating electrical signal at ultrasonic frequencies. This creates compression waves in the fluid tank that helps the coating process [10,11].

The method using ultrasonic can improve the agitating process during electroplating process. Transfer of electric current metal ions can be through an electrolyte solution with the help of ultrasonic batch. The particles from the electrolyte solution can be divided into smaller and dissolved electrolyte ions in the electrolyte will settle evenly on the solid to be coated. The quality of coating substrate can be improved. Conventional coating electroplating method has been done but its quality is relatively worsh. This paper discusses improved electroplating processes supported by ultrasonic batch.

\subsection{Nickel As Metal Coating}

The coating process there are several elements found in the periodic table can be used as a coating material. Nickel is a chemical element whose symbol is $\mathrm{Ni}$ and atomic number 28 . Nickel is a metal element with solid phase. At this time, nickel plating in iron is widely performed both for the purpose of preventing rust and beauty. The properties possessed by nickel are contained in table 1 [12]. 
Table 1. Properties of the element nickel

\begin{tabular}{|c|c|}
\hline Criteria & Specification \\
\hline crystal structure & FCC \\
\hline atomic mass & $58.7 \mathrm{gr} / \mathrm{mol}$ \\
\hline Density & $8.907 \mathrm{gr} / \mathrm{cm}^{3}$ \\
\hline melting point & $1453^{\circ} \mathrm{C}$ \\
\hline boiling point & $2730^{\circ} \mathrm{C}$ \\
\hline Tensile strength & $317 \mathrm{MPa}$ \\
\hline Yield strength & $59 \mathrm{MPa}$ \\
\hline Hardness & 64 HV (annealed) \\
\hline
\end{tabular}

\section{Materials and Methods}

\subsection{Stainless Steel AISI 304 As a metal coated (Substrate)}

Stainless steel AISI 304 is an austenitic stainless containing chromium and nickel elements of $18-20 \%$ wt and $8-10.5 \%$ wt respectively. These elements are the alloying elements most commonly produced and used amongst all stainless steel [13].

\subsection{Copper (CU)}

Copper is a transition metal (group I B) is reddish, easy to filter and easy to work metal. Brass or copper $(\mathrm{Cu})$ is generally crystalline and reddish color. One of the metal from the IB with atomic number 29; the atomic weight is 63.546 ; melting point $1083^{\circ} \mathrm{C}$; Boiling point $2310^{\circ} \mathrm{C}$ [14].

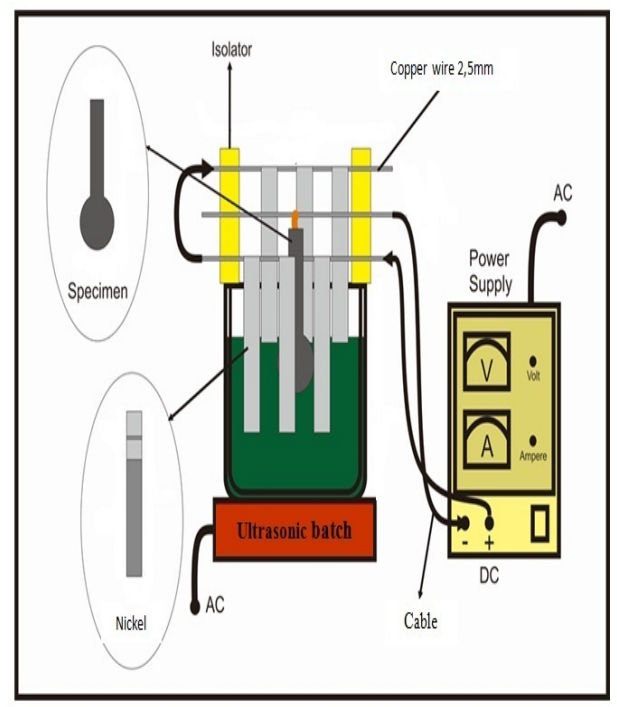

a)

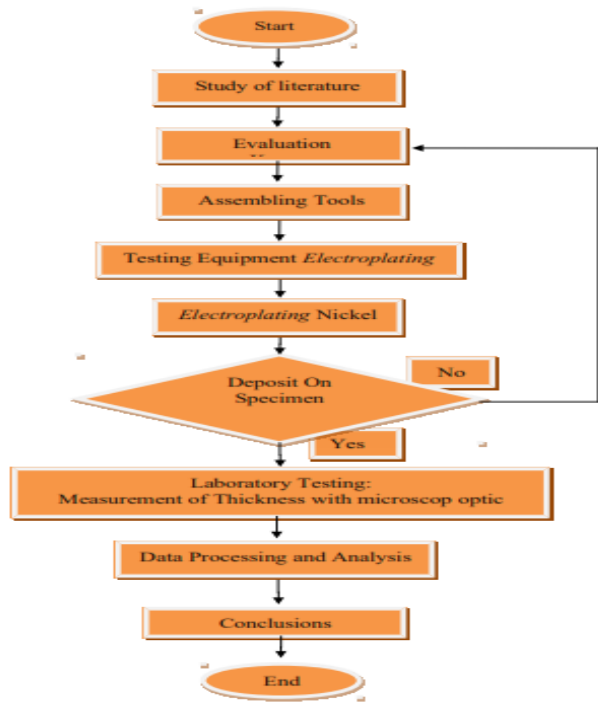

b)

Fig 1. a). The illustration of experiment tools and b). Flow chart of process. 


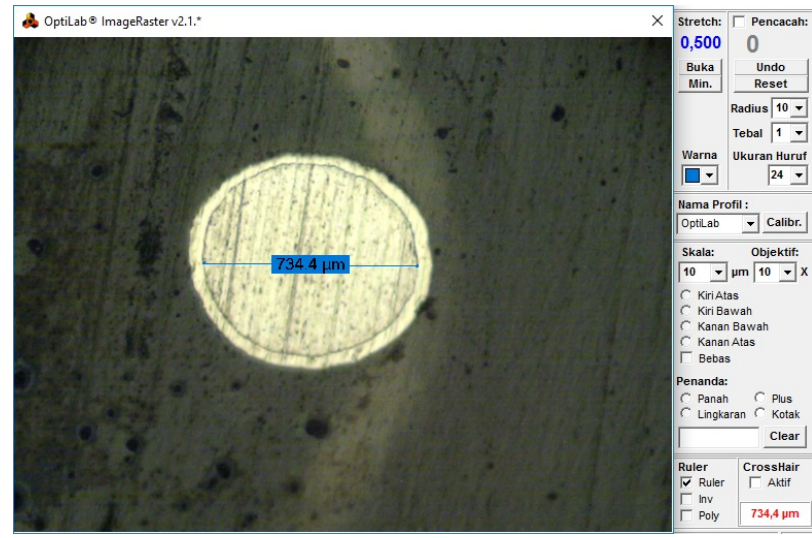

Fig 2. Dimensional Image Measurement by Optical Microscopes.

\section{Result and Discussion}

The weight and thickness of the specimen (deposit) is obtained by a nickel electroplating process with 1.5 amperes of electric current and time layer (60, 120, 180 seconds). This section also displays tabular data and images on the nickel micro layer thickness. Tables and figures can shows the effect of electric current and the thickness of the coating layer of time on nickel.

\subsection{Measurement of weight and thickness}

The measurements of the weight specimens and the thickness layer of nickel on the research done by destructive methods. Weight measurement with digital scales and thickness measurements made using optical microscope assisted by software imageraster.

Table 2. 304 stainless steel weight data on the process of electroplating nickel.

\begin{tabular}{|c|c|c|c|c|c|c|c|}
\hline \multirow{2}{*}{ No } & \multirow{2}{*}{$\begin{array}{c}\text { ELECTRO } \\
\text { PLATING }\end{array}$} & \multicolumn{4}{|c|}{ WITHOUT ULTRASONIC BATCH } & \multicolumn{3}{|c|}{ USING ULTRASONIC BATCH } \\
\cline { 3 - 8 } & & $60 \mathrm{~s}$ & $120 \mathrm{~s}$ & $180 \mathrm{~s}$ & $60 \mathrm{~s}$ & $120 \mathrm{~s}$ & $180 \mathrm{~s}$ \\
\hline 1 & Before & $10.7573 \mathrm{~g}$ & $10.7498 \mathrm{~g}$ & $10.7624 \mathrm{~g}$ & $10.7778 \mathrm{~g}$ & $11.7893 \mathrm{~g}$ & $11.7629 \mathrm{~g}$ \\
\hline 2 & After & $10.7811 \mathrm{~g}$ & $10.7988 \mathrm{~g}$ & $10.8395 \mathrm{~g}$ & $10.8281 \mathrm{~g}$ & $11.8631 \mathrm{~g}$ & $11.8705 \mathrm{~g}$ \\
\hline
\end{tabular}

Table 3. Copper weight data on the process of electroplating nickel.

\begin{tabular}{|c|c|c|c|c|c|c|c|}
\hline \multirow{2}{*}{ No } & \multirow{2}{*}{$\begin{array}{l}\text { ELECTRO } \\
\text { PLATING }\end{array}$} & \multicolumn{3}{|c|}{ WITHOUT ULTRASONIC BATCH } & \multicolumn{3}{|c|}{ USING ULTRASONIC BATCH } \\
\cline { 3 - 8 } & & $60 \mathrm{~s}$ & $120 \mathrm{~s}$ & $180 \mathrm{~s}$ & $60 \mathrm{~s}$ & $120 \mathrm{~s}$ & $180 \mathrm{~s}$ \\
\hline 1 & Before & $11.7578 \mathrm{~g}$ & $11.7593 \mathrm{~g}$ & $11.7629 \mathrm{~g}$ & $11.7598 \mathrm{~g}$ & $11.7693 \mathrm{~g}$ & $11.7711 \mathrm{~g}$ \\
\hline 2 & After & $11.7811 \mathrm{~g}$ & $11.8031 \mathrm{~g}$ & $11.8305 \mathrm{~g}$ & $11.8011 \mathrm{~g}$ & $11.8431 \mathrm{~g}$ & $11.8875 \mathrm{~g}$ \\
\hline
\end{tabular}

Table 2 and 3, the weight measurement using digital scales shows that the copper has a heavier specimens. That's because copper has heat conductivity and electrical conduction better than others. The copper also has a low chemical reactivity. During the process, the nickel particles are dissolved in a solution which will more easily stick to copper 
specimens. The nickel layer on copper specimens is thicker and increases heavy specimens. The nickel layer on copper specimens is thicker and increases weight specimens.

Table 4. The thickness stainless steel 304 using electroplating 1.5 Ampere.

\begin{tabular}{|c|c|c|c|c|c|}
\hline No & $\begin{array}{c}\text { Electric } \\
\text { Current(A) }\end{array}$ & $\begin{array}{c}\text { Temperature } \\
\left({ }^{\circ} \mathrm{C}\right)\end{array}$ & $\begin{array}{c}\text { Time } \\
(\mathrm{s})\end{array}$ & $\begin{array}{c}\text { Thickness coating } \\
\text { without us }(\mu \mathrm{m})\end{array}$ & $\begin{array}{c}\text { Thickness } \\
\text { coating using } \\
\text { us }(\mu \mathrm{m})\end{array}$ \\
\hline 1 & 1.5 & 45 & 60 & 4.36 & 7.57 \\
\hline 2 & 1.5 & 45 & 120 & 6.66 & 10.82 \\
\hline 3 & 1.5 & 45 & 180 & 8.27 & 14.90 \\
\hline
\end{tabular}

Table 5. The thickness copper using electroplating 1.5 Ampere.

\begin{tabular}{|c|c|c|c|c|c|}
\hline No & $\begin{array}{c}\text { Electric } \\
\text { Current } \\
(\mathrm{A})\end{array}$ & $\begin{array}{c}\text { Temperature } \\
\left({ }^{\circ} \mathrm{C}\right)\end{array}$ & $\begin{array}{c}\text { Time } \\
(\mathrm{s})\end{array}$ & $\begin{array}{c}\text { Thickness coating } \\
\text { without us }(\mu \mathrm{m})\end{array}$ & $\begin{array}{c}\text { Thickness } \\
\text { coating using } \\
\text { us }(\mu \mathrm{m})\end{array}$ \\
\hline 1 & 1.5 & 45 & 60 & 5.76 & 11.34 \\
\hline 2 & 1.5 & 45 & 120 & 8.58 & 18.75 \\
\hline 3 & 1.5 & 45 & 180 & 11.60 & 26.50 \\
\hline
\end{tabular}

Table 4 and 5 show that the effect of time on coating thickness. The longer time will produce the thicker coating. It was caused by the dissolved metal having time to finish evenly and accumulate on the coated object. Electroplating process is supported by using ultrasonic, can improve the agitating electrolyte process during the process.

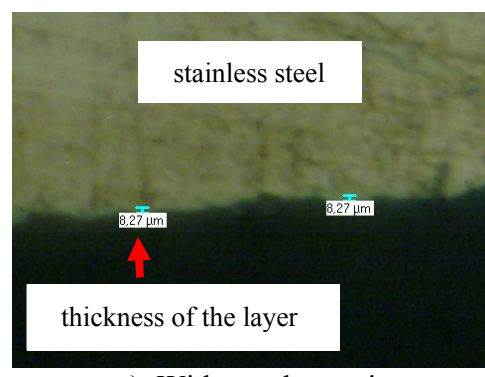

a). Without ultrasonic

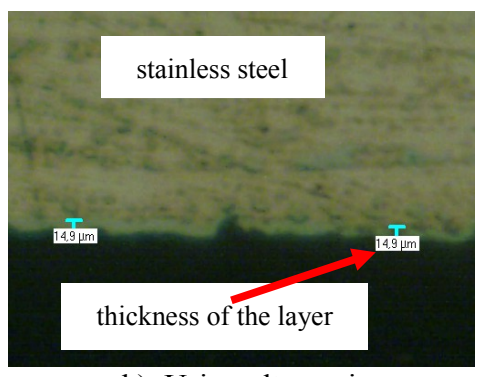

b). Using ultrasonic

Fig 3. a). Thickness coating of $6.27 \mu \mathrm{m}$ at SS 304 and b). The thickness of $14.9 \mu \mathrm{m}$ using ultrasonic at SS 304.

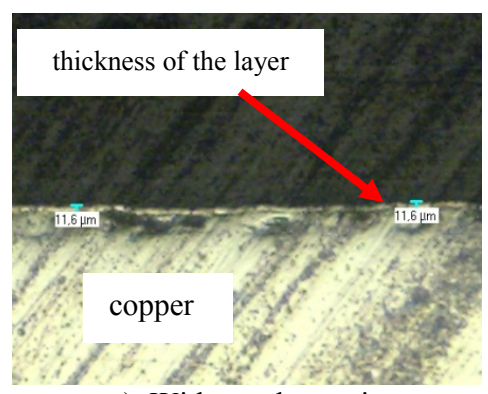

a). Without ultrasonic

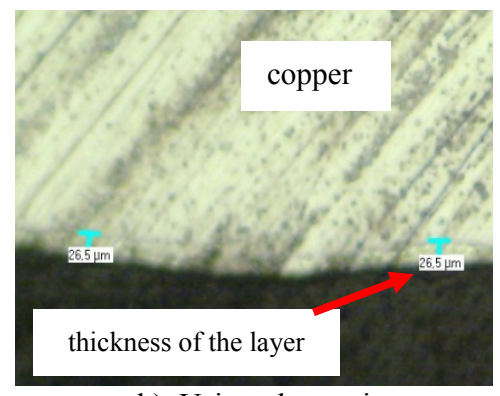

b). Using ultrasonic

Fig 4. The coating of copper substrate a). The thickness of $11.6 \mu \mathrm{m}$ without ultrasonic and b). The thickness $26.5 \mu \mathrm{m}$ using ultrasonic. 
Fig. 3 and 4 show the electroplating thickness using ultrasonic and without ultrasonic. Fig. 3 shows the electroplating thickness on the stainless steel substrate. The thickness is $11.6 \mu \mathrm{m}$ without using ultrasonic batch, when using ultrasonic thickness $14.9 \mu \mathrm{m}$. Fig. 4 shows the electroplating thickness of the copper substrate. The thickness is $11.6 \mu \mathrm{m}$ without ultrasonic and $16.5 \mu \mathrm{m}$ using ultrasonic. Electroplating processes supported by ultrasonic produce a better thickness coating than without ultrasonic. Ultrasonic equipment during the process can improve the process especially agitating electrolytes which can increase the addering of the nickel particles in the substrate.

\section{Conclusions}

Several conclusions can be presented as follows :

The composition of nickel electrolyte solutions using nickel sulfate $300 \mathrm{gr} / \mathrm{L}$, nickel chloride $30 \mathrm{gr} / \mathrm{L}$, and sour borak $30 \mathrm{gr} / \mathrm{L}$ with brighteners added one (I) $15 \mathrm{~mL}$ and brighteners two (II) $1 \mathrm{~mL}$. The electroplating process can be enhanced by using ultrasonic for stainless stell and copper substrate. The process of electric current and electroplating time is directly proportional to the thickness of the layer (deposit). The best process electrode is obtained on the copper substrate. The best process was obtained using $1.5 \mathrm{~A}$ and 180 seconds and a thickness higher than $26.50 \mu \mathrm{m}$.

\section{Reference}

1. M. Kumar, S. Mishra, R. Mitra, Surf. Coat. Technol. 228 (2013).

2. A.M. Pagon, E.D. Doyle, D.G. McCulloch, Surf. Coat. Technol. 235 (2013).

3. S.S. Djokic, Theory and Practice, Springer Science \& Business Media, (2010).

4. Yli-Pentti, A. Electroplating and Electroless Plating, (Finlandia 2014).

5. K.H. Kim, T.Lim, K.J. Park, H.C. Koo, M.J. Kim, J.J. Kim, 151 (2015).

6. Y. Jie, H. Fan, J.R. Niskala, W. You, Surf. A-Physicochem. Eng. Asp,. 434 (2013).

7. Mordechay Schlesinger, M.P. Modern Electroplating, (John Wiley \& Sons Metallography test 2010).

8. B. Díaza, J. S'wiatowska, V. Maurice, A. Seyeux, E. Härkönen, M. Ritala, S. Tervakangas, J. Kolehmainen, P. Marcus, 90 (2013).

9. K. Asa Deepthi, R. Balachandran, B.H. Ong, K.B. Tan, H.Y. Wong, H.K. Yow, S. Srimala, Appl. Surf. Sci., 360 (2016).

10. Fuchs, F. John. Ultrasonic Cleaning: Fundamental Theory and Application. (Blackstoney Ultrasonic 2010).

11. AO L, HAO H, JI S H, FANG C F, ZHANG X G. Transactions of Nonferrous Metals Society of China, 6 (2011).

12. Bardet, W.P. ASM HANBOOK Surface Engineering, (ASM International 1994).

13. DiBari, G., Nickel Plating Handbook, (Canada 2014).

14. Marco Boniardi, A.C., Stainless steels. (Gruppo Lucefin Research \& Development 2014).

15. I.V. Blinkov, S.G. Tsareva, A.V. Zentseva, A.O. Volkhonskii, V.I. Buzanov, N.N. Stepareva, Russ. J. Non-Ferrous Met., 51 (2010). 